\title{
Alfabetização e letramento: construindo saberes essenciais
}

\author{
Reading, writing and literacy: building essential \\ knowledge
}

\author{
Anézio Cláudio BERNARDES \\ Maria Angélica Gomes MAIA \\ Vera Lúcia Catoto DIAS \\ Ana Enedi Prince SILVA
}

\section{RESUMO}

Este trabalho tem como objetivo verificar os entraves que inviabilizaram, ao longo da história educacional brasileira, o acesso de crianças pertencentes às classes populares na rede pública de ensino, e verificar, também, a importância da escola como instância sócio-cultural. Procura percorrer uma trilha de investigação teórica sobre essa agência denominada escola e, para isso, fundamenta-se nos pressupostos de Ferreiro, Silva e Branco, dentre outros autores. Os resultados desta pesquisa apontam que, no contexto escolar, instalam-se possibilidades reais de consecução das metas previstas para o processo de ensino e aprendizagem; e - mais especificamente -, para a efetivação construção e apropriação da língua, ato de ler e escrever, em um ambiente em que as salas de aulas podem se configurar, dependendo dos que nela atuam, em pontos de partida para a construção de conhecimentos significativos.

Palavras-chave: Alfabetização e letramento, escola pública, ensino e aprendizagem, métodos, políticas públicas. 


\begin{abstract}
The objective of this work is to identify the obstacles that, along the Brazilian history, denied the access to public schools for poor family children. The importance of the school as a socio-cultural instance will also be studied. In order to follow a theoretical investigative trek on the institution school, it is based on the assumptions of Ferreiro, Silva e Branco, among others. The results of this research show that, in the school context, there are real possibilities that permit to reach the proposed goals; more specifically, for the effective language construction and appropriation, the act of writing and reading in a school class environment, depending on the actors involved, towards the establishment of meaningful knowledge.
\end{abstract}

Index terms: Reading, writing and literacy, public school, teaching and learning methods, public policy.

\title{
1. INTRODUÇÃO
}

Este trabalho tem por metas verificar os entraves que - durante a história educacional brasileira - inviabilizaram o acesso de crianças de classes sociais menos favorecidas na rede pública de ensino; e verificar, também, a importância do contexto escolar como instância sócio-cultural.

Para a consecução desses objetivos, privilegiou-se, nesta pesquisa, uma investigação teórica, fundamentada nos pressupostos, dentre outros, de Ferreiro (1991), para quem “os que fracassam na escola não são diferentes dos que têm sucesso"; Silva (1998), a qual tece considerações relativas à história da alfabetização no Brasil; e Branco (1997), que discorre sobre o trabalho cotidiano do professor na escola.

\section{A HISTÓRIA E A ESCOLA NOS ANOS INICIAIS DO BRASIL REPÚBLICA}


No Brasil República, segundo Silva (1998), o País se preparava para a implantação do capitalismo, a mão-de-obra imigrante substituiria a escrava, uma vez que a Abolição se encarregara de preparar uma sociedade de homens livres.

Nesse contexto, a sociedade urbana clamava por escolaridade, embora, ainda, como instrumento de prestígio e poder, completamente dissociada das necessidades sociais e econômicas da época, uma vez que a expansão das camadas médias aumentaria a demanda por educação na busca de caminhos de ascensão social, bem como a expansão industrial exigiria a preparação profissional de mão-de-obra.

Com a revolução de 1930, surgiu uma movimentação organizada por parte da classe média urbana que buscava, na escolaridade, a possibilidade de preencher os cargos burocráticos existentes.

A escola, tal qual a concebemos, é uma instituição recente, principalmente quando nos referimos à escola pública, destinada às camadas populares da sociedade. Sabemos que, a partir de 1960, quando ela se compromete, de fato, a assumir a alfabetização das classes populares, as condições de trabalho de seus agentes impedem que a quantidade se alie à qualidade.

Isso porque o acesso à leitura e à escrita, por parte de toda a população brasileira, estava, constantemente, na pauta de planos de governos e era o foco de muitos partidos políticos autoritários e/ou democráticos. No entanto, apenas o discurso a favor da escolarização básica da população brasileira freqüentemente era o suficiente para alcançar os objetivos políticos desses partidos, uma vez que o que sempre faltou, nesses discursos e campanhas, foi o ingrediente básico que move e torna real todo e qualquer discurso, sonho e ideário: “vontade”, transformada em ações reais efetivas que, muito além de serem apenas utopias, concretizam-se com seriedade e a constância nas ações. 
Ao término da Segunda Guerra Mundial, essa situação se intensificou e culminou com o Golpe Militar de 1964, em que a reorganização do Ensino foi encomendada a organizações internacionais, tendo como objetivo a democratização do ensino e, conseqüentemente, o acesso à escola pública a todos os cidadãos brasileiros. Pela primeira vez, no Brasil, essa possibilidade parecia viável.

Para alcançar esse objetivo, a iniciativa privada foi chamada a participar. Resgatou-se, nesse momento, a concepção social do Brasil Colônia: às camadas populares subalternas, eram reservados os trabalhos braçais e o acesso à escola pública; às camadas superiores dominantes, eram oferecidos, em escolas particulares, o trabalho teórico e a elaboração do planejamento intelectual.

O ano de 1964 marcou um momento importante, uma vez que a organização política foi alterada pela ditadura militar: o modelo econômico que se consolidou no Brasil foi de capital internacional, voltado para o exterior; as mudanças chegaram ao Sistema Educacional Brasileiro; o modelo de educação escolhido, para ser implantado no Brasil, foi desenvolvido nos Estados Unidos da América, para os países em desenvolvimento.

As reivindicações, feitas pela classe média, por maior número de vagas para a universidade, tiveram como resposta a reorganização do Sistema Educacional Brasileiro direcionado a cursos de nível técnico, pois, consumada a instalação das empresas multinacionais no País, buscava-se mão-de-obra especializada. Tal fato ocorreu visto que "as forças produtoras e as relações de produção características do capitalismo somente se concretizam e expandem num universo de valores, idéias, noções e doutrinas apropriadas” (IANNI, 1976).

A LDBEN n 5692/71, que fixou diretrizes e bases para o ensino de primeiro e segundo graus, foi sancionada pelo, então, Presidente Emílio G. 
Médici, pelo Ministro da Educação, Jarbas Passarinho, e pelo Secretário Geral do Ministério, Júlio Barata, em 11 de agosto de 1971, para respaldar, legalmente, a reforma da educação brasileira.

Com a obrigatoriedade do ensino de primeiro grau, o Estado abarcou a responsabilidade pelo ensino público dirigido às classes populares da sociedade brasileira. Com essa medida, pela primeira vez, de fato, ampliouse o acesso à escola pública, e, conseqüentemente:

[...] a expansão das matrículas provocou mudanças no cenário tradicional da escola: salas maiores, períodos intermediários, recrutamento de novos professores; muitos egressos de instituições de ensino precárias; tumultos no processo de adaptação às mudanças curriculares e aos critérios de aprovação, enfim um conjunto de fatores que dificultou a compreensão do que havia de mais relevante acontecendo no cenário escolar (BRANCO, 1997, p.28).

A reorganização do ensino no Brasil - idealizada nos Estados Unidos, implantada e assessorada por técnicos e especialistas americanos -, não era um modelo educacional para americanos, era para brasileiros, isso porque em nenhum momento se enfatizou a educação como prioridade e sim como necessidade restrita à mão-de-obra.

O modelo econômico implantado foi o capitalista para países periféricos, em que a competitividade, o individualismo e o consumo desenfreados são priorizados em detrimento de políticas sociais. A escola pública brasileira entrou em período que mais tarde se denominaria, não muito apropriadamente, de redemocratização do ensino.

Nesse período:

[...] nossa escola de pouquíssimas horas se especializou, desde então, ao atendimento a crianças das classes médias, que já chegam a ela bem preparadas à alfabetização. Têm casa onde se lê e onde há uma pessoa já escolarizada que as ajuda nos estudos. A criança popular, que não tem tal casa, nem ajuda, porque provém de família sem escolaridade prévia, vê-se 
condenada à reprovação. Repete, necessariamente, a primeira série, tempo de domesticar a mão para manipular o lápis e de entender a estranha fala da professora. Nada disso sendo valorizado pela escola, ela é obrigada a repetir seguidas vezes a mesma série. Daí em diante progride, de fracasso em fracasso (RIBEIRO, 1995, p. 123).

Contrariamente ao planejado, uma vez implantada a reforma do ensino, os tropeços começaram a acontecer. Apesar do sistema administrativo-burocrático encarregar-se de tutelar o processo pedagógico, os currículos das propostas nos cursos de formação dos profissionais de ensino não se efetivaram, ao contrário, obstruíram o processo planejado. Assim, uma vez que os professores apresentavam total desconhecimento para com a clientela que ora ocupava os bancos escolares, o que resultou em uma escola para classes populares, mas que, na verdade, buscava o aluno idealizado de classe média, e, conforme Branco:

[...] o convívio com professores ilustra com suas queixas as dificuldades com que se deparam no dia a dia de seu trabalho. Relatam que mandam bilhetes aos pais informando faltas de lições e trabalhos, solicitando seu comparecimento à escola para conversas com vistas à melhoria do aproveitamento escolar de seu filho e que não obtêm respostas. Contam também que os pais não comparecem às reuniões e concluem, por todas essas coisas, que os pais não se interessam pela escolarização de seus filhos. Isto poderia ser verdadeiro se todos os pais fossem alfabetizados para poder ler os bilhetes e respondê-los, se as reuniões não colidissem com os horários de trabalho dos pais que, em tempo de desemprego, não podem se dar ao luxo de vê-lo ameaçado (BRANCO, 1997, p. 56).

\section{ANOS NOVENTA: NOVOS ARES}

Em 20 de dezembro de 1996, foi promulgada a Lei de Diretrizes e Bases da Educação Nacional (LDBEN), Lei número 9394/96, que trata da organização do Sistema de Ensino e de uma Base Curricular Comum para 
todo o território brasileiro, sob a orientação dos Parâmetros Curriculares Nacionais (PCNs).

A LDBEN possibilita a reorganização do Ensino na Rede Estadual de Ensino, por meio da Deliberação do Conselho Estadual de Educação (CEE) $n^{\circ} 9 / 97$, que se refere aos oito anos iniciais de escolaridade do Ensino Fundamental, compreendendo uma estrutura didática organizada em dois segmentos: O Ciclo I refere-se aos quatro anos iniciais do Ensino Fundamental; o Ciclo II, os quatro anos finais do Ensino Fundamental.

Nos ciclos, a forma de educação escolar é a de Progressão Continuada. Para compreender melhor o ensino em ciclos, é necessário o conhecimento da Teoria do Desenvolvimento de Piaget e colaboradores. Para esse autor:

[...] a ação humana consiste neste movimento contínuo e perpétuo de equilibração. É por isto que, nas fases de reajustamento ou equilibração inicial, se pode considerar as estruturas mentais sucessivas que produzem o desenvolvimento como formas de equilíbrio, onde cada uma constitui um progresso sobre as precedentes. Mas também é preciso compreender que este mecanismo funcional, por mais geral que seja, não explica o conteúdo ou estrutura das diferentes necessidades, pois cada uma dentre elas é relativa à organização do nível considerado (PIAGET, 1989, p. 78).

Sendo assim, os interesses de uma criança dependem, portanto, a cada momento, do conjunto de suas noções adquiridas e de suas disposições afetivas, já que estas tendem a completá-los em busca de melhor equilíbrio.

Dessa forma, por meio dos ciclos e pelo regime de progressão continuada, é possível desenvolver uma ação pedagógica alicerçada na aprendizagem, a fim de deslocar o foco do processo do ensino para o da aprendizagem; ou seja, a meta, agora, é o processo de construção da aprendizagem, não mais a simples identificação das dificuldades como condição individual do aprendiz. 
A partir de 1998, a Secretaria de Educação do Estado de São Paulo vem desenvolvendo a nova organização do ensino que visa à aprendizagem da maioria dos alunos, uma vez que ainda persistem, no contexto escolar, problemas de aprendizagem gerados em períodos anteriores, uma vez que:

[...] o acesso ao conhecimento é um benefício social a que toda criança tem direito e é a razão de ser da própria escola. Quando esta simplesmente classifica e separa os que considera mais capazes de prosseguir os estudos nas séries subseqüentes, acaba penalizando justamente os que mais precisam dela, os alunos pertencentes às classes sociais mais desfavorecidas e mais distantes da cultura escolar (FDE, 1998).

O percurso identificado pela trajetória de escolaridade dos alunos das classes populares na escola pública tem sido permeado, em grande porcentagem, pelo fracasso, salvo experiências isoladas, que se constituem em ilhas de excelência. Os resultados necessitam ser analisados para que se possa reverter essa realidade, uma vez que a exigência do mundo globalizado aponta para cidadãos não só alfabetizados, mas também letrados.

Nesse panorama de espaço-tempo em que a educação ocorre, pretendemos tecer considerações relacionadas à prática de alfabetização que se processa no contexto atual, após as contribuições da psicologia genética de Piaget; os quase vinte anos da publicação das idéias sobre a psicogênese da aquisição da leitura e escrita, estudada por Ferreiro e Teberosky. Estas autoras, nos anos 80, afirmam que o processo de ensino e aprendizagem é estudado a partir do sujeito cognoscente, as contribuições das áreas da sociologia, psicolingüística, psicologia que, de forma rica e sólida, aprimoraram as nossas visões acerca do processo de ensino e aprendizagem da língua materna, -, centrando-se, agora, no como a criança aprende.

Acrescenta-se a esse contexto, particularmente, as nossas investigações como professores alfabetizadores e "formadores de 
formadores”, uma vez que utilizamos, em nossa prática docente, as contribuições relativas ao Letramento, termo saído da psicologia social e que, gradativamente, vai se incorporando ao conceito de alfabetização.

Assim, vamos caminhando com a intenção de entender e investigar o saber sobre a alfabetização e o fazer alfabetização: tarefa sempre árdua quando o ponto de partida é não encerrar o assunto e sim revisitar as questões incomodativas inerentes a esse processo.

\section{ALFABETIZAÇÃO NO ESTADO DE SÃO PAULO}

Revendo as formas tradicionais pela qual a alfabetização se realizou no contexto escolar, percebemos que, antes dos anos oitenta, a questão central que se apresentava era a crença que os educadores depositavam na eficácia dos métodos analíticos e sintéticos. Encontra-se no pensamento de Ferreiro a constatação dessa valorização sobre o método, no imaginário do professor. Para essa autora:

[...] a preocupação dos educadores tem-se voltado para busca do "melhor" ou mais eficaz deles, levando-se, assim, uma polêmica em torno de dois tipos fundamentais: métodos sintéticos, que partem de elementos menores que a palavra, e métodos analíticos, que partem da palavra ou unidades maiores (FERREIRO, 1991, p. 18).

Em relação a esses métodos, é interessante notar que se parte do pressuposto de que cada som corresponde a uma letra e esta era a grande tarefa do professor, levar o aluno, a saber, qual letra representava qual som, e vice-versa.

Para o domínio desse processo, o trabalho do professor apoiava-se, quase que exclusivamente, na cartilha. Nesse tipo de abordagem tradicional, 
o pressuposto teórico que norteava essas concepções didáticas era o caráter passivo da aprendizagem.

No final da década de 70, a Secretaria Estadual da Educação do Estado de São Paulo (SEE/SP) realizou pesquisas para identificar e quantificar a extensão dos problemas da repetência e evasão. Os resultados mostraram que mais de $40 \%$ de crianças eram reprovadas na primeira série. Esse quadro apresentou-se mais crítico nas regiões em que se concentrava a população menos favorecida, a periferia urbana, onde os índices porcentuais apontaram para $70 \%$ dos alunos.

A Secretaria de Estado da Educação, após extenso período em que os educadores se viram apartados do debate e da reflexão educacional, em virtude do excessivo centralismo vigente em nossas políticas públicas e do autoritarismo embutidos nessas mesmas políticas, reinicia um longo processo de discussão que, pode-se dizer, perdura até hoje no sistema de ensino paulista.

Nesse ano, o parecer do Conselho Estadual de Educação, CEE n¹913/83, publicado no Diário Oficial de 31/12/83, aprova a implantação do Ciclo Básico (CB), na rede estadual de ensino. No início do ano letivo de 1984, o Ciclo Básico foi implantado e, para que os resultados pretendidos fossem bem sucedidos, algumas medidas foram traduzidas por: decretos, pareceres, resoluções e comunicados, dentre outros. Enfim, a rede se mobilizou para estancar a reprovação em massa das classes populares, uma vez que, conforme a Secretaria da Educação, “embora a Constituição Federal garanta o direito à escola gratuita, dos sete aos quatorze anos, o problema continua sendo o de não garantir, de fato, a escolarização pela impossibilidade de permanência e efetiva aprendizagem escola” (ATPCE/CENP, 1987).

A SEE/SP, ao optar pela aprendizagem em ciclo, respaldou-se nos trabalhos de desenvolvimento humano de Piaget e na pesquisa sobre a 
construção da escrita de Ferreiro e Teberosky, resultados socializados na década de 1980. Como primeira meta para a superação dos problemas de aprendizagem dos alunos das classes populares, foi buscar fundamentação teórica que fosse mais adequada à realidade da escola pública:

\begin{abstract}
Por ora, começamos a compreender que os que fracassam na escola não são diferentes dos que têm sucesso. Para todos eles, o desenvolvimento da leitura-e-da-escrita é um processo construtivo. A informação disponível, inclusive a informação sistemática propiciada pela escola, é apenas um dos fatores intervenientes. Se as crianças testam, com tanto esforço, diversas hipóteses estranhas a nosso modo de pensar, por alguma razão há de ser (FERREIRO, 1991, p. 60).
\end{abstract}

Ancorada em aportes teóricos, a Secretaria de Educação cuidou para que outras ações consubstanciassem a implantação de um projeto para o Ciclo Básico; sendo seus objetivos específicos: informar a todos no âmbito educacional sobre o $\mathrm{CB}$ e socializar conhecimentos; sensibilizar profissionais de educação para que se comprometessem com os objetivos do projeto, ou seja, estancar a reprovação; elaborar material específico; garantir um número máximo de alunos por sala (trinta e cinco); propiciar, aos professores incluídos no Projeto, acompanhamento pedagógico; estender a carga horária em duas horas/dias, para os alunos e os professores; garantir o desenvolvimento de metodologia diferenciada; e complementar a alimentação para a dieta das crianças, pois passaram a ficar seis horas/dia na escola.

As discussões, iniciadas na década de 80 , e a proposta de reorganização do sistema por intermédio do Ciclo Básico e da Jornada Única, instituída pelo Decreto $n^{\circ} 21.833$ de 28/12/83 foram caracterizados por integrar, de forma contínua, o processo de ensino e aprendizagem correspondente às duas primeiras séries do primeiro grau. Estes propiciaram a reorganização gradativa do trabalho escolar, de forma a tratar 
adequadamente as necessidades de aprendizagem dos alunos, no decorrer do período dos dois primeiros anos letivos de escolarização.

O objetivo, agora, era de avançar nas concepções e crenças dos educadores, para que se conscientizassem de que o ensino da língua materna era muito mais que uma questão de método. Para isso, foram produzidos materiais instrucionais, especialmente para a área de alfabetização, pela Coordenadoria de Estudos e Normas Pedagógicas (CENP). Esses materiais expressavam e guardam até hoje as marcas, concepções e ações políticas de uma época, deixando-nos compreender sobre as intenções acerca do processo de aquisição da leitura e da escrita.

Após esse período de reflexão, fruto dos conhecimentos trazidos pelas pesquisadoras Ferreiro e Teberosky, as quais se pautam nas contribuições da psicologia genética de Piaget, começamos a centrar nossas ações e nossa concepção de conhecimento e alfabetização a partir do sujeito aprendiz, a maneira como ele organiza o aprendizado, seus conhecimentos prévios a respeito da linguagem começam a ser investigados e considerados na concepção dos educadores.

As concepções piagetianas apontam que o sujeito cognoscente busca apreender e compreender, por meio dos seus próprios mecanismos, em interação com o mundo. Por conseguinte, a representação de aprendizagem e a intervenção docente nem sempre coadunam com o tempo interno de aprendizagem dos sujeitos aprendizes, o que acaba justificando a consolidação e a manutenção, na escola, do trabalho por seriação e não por ciclo. Percebe-se, dessa forma, que há um descompasso entre o que é teorizado e aquilo que, posteriormente, é oficializado, como foi o caso da proposta do Ciclo Básico.

Sabemos da complexidade que é intervir na crença dos fazeres pedagógicos dos educadores, o quanto prescrever um currículo, fazer uma 
proposta ou mesmo estabelecer diretrizes educacionais é mais profundo e complexo do que se pensa. Esse se constitui no grande desafio da academia, de quem pensa educação: estabelecer o equilíbrio e a consonância entre a teoria, a prática docente e o real cotidiano multifacetado do universo da instituição escolar e seus protagonistas.

Vivemos, pela nossa história de descontinuidade política, em constante transição em relação ao caminho do aprendizado da língua materna, e, como aponta Freire, “a transição se torna então tempo de opções. Nutrindo-se de mudanças, a transição é mais que mudança. Implica realmente na marcha que faz a sociedade na procura de novos temas, de novas tarefas ou, mais preciosamente, de sua objetivação” (1989, p. 65).

Cada vez mais, como sujeitos históricos, confirmamos que conhecer não é e não pode ser um ato isolado. O conhecimento faz parte de um processo que se caracteriza, fundamentalmente, pela sua pessoalidade e interação incessante.

\section{ALFABETIZAÇÃO E LETRAMENTO}

Em relação ao aprendizado da lectoescrita (aprendizado da leitura e das escrita), temos observado que os métodos tradicionais de alfabetização vêm, ainda, insistindo na afirmativa de querer ensinar essa competência, de forma empírica, a partir da verbalização, treino visual e motor, e da demonstração reiterada e repetitiva da relação existente entre a escrita alfabética e os aspectos sonoros da fala. Partem do pressuposto de que essa relação pode ser ensinada por meio do ensino descontextualizado e mecânico, do vínculo entre as letras e os fonemas, como se essa relação fosse aprendida passivamente, e não como fruto de construção real em interação com a linguagem escrita. 
Esse conceito só reafirma a limitação do termo alfabetização como vem sendo entendido e praticado ainda hoje na escola - domínio do código da leitura e da escrita. Nesse momento, ressaltamos a importância dos estudos acerca do letramento - denominação cunhada em 1996, segundo Soares (1998), por Kato e que vem sendo utilizada na educação e nas ciências lingüísticas, a partir da segunda metade dos anos oitenta. No Brasil, a pesquisa sobre letramento vem sendo desenvolvida, principalmente, por Ângela Kleiman e Magda Soares, com o objetivo de explicar o efeito social da escrita nos estudos sobre alfabetização.

Para definir o termo Letramento, recorremos à obra de Magda Soares "Letramento: um tema em três gêneros", na qual, a partir de estudos de outros autores, a autora busca pontuar o termo no campo da Educação e das Ciências Lingüísticas.

Nesse sentido, a escrita é vista, dentro do Letramento, como um processo de real democratização da cultura, e não apenas como um objeto da atividade escolar. $\mathrm{O}$ letramento traz à tona o caráter social da escrita: extrapola o caráter limitador da alfabetização por abarcar e legitimar estratégias e vivências construídas e desenvolvidas pelo sujeito no seu cotidiano para situações de uso da leitura e da escrita.

Entendemos o letramento como uma possibilidade real em que o ser humano vivencia a função social do uso da leitura e da escrita. Reafirmamos assim o caráter ancestral de aprender e viver em grupo próprio de sua espécie, uma vez que, segundo Colello (1995, p. 11), “ao contrário dos animais, cujas bases fisiológicas determinam suas possibilidades e limites, o homem conta com um equipamento não corpóreo - a razão - que lhe permite uma infinidade de oportunidades na manifestação de si”.

Encontramos ainda na mesma autora que; 
[...] aproveitando-se da tradição, das convenções e das conquistas de seus antepassados, a cultura é construída a partir de intercâmbios entre os homens. Ela seria impossível se o indivíduo encerrasse em si a sua história de vida” (COLELLO, 1995, p. 12).

Durante décadas, os estudos e práticas pedagógicas ignoraram os conhecimentos prévios e os usos sociais que os aprendizes faziam da linguagem, bem como as suas práticas antes do seu ingresso no ambiente escolar.

Por essas práticas discentes estarem recheadas de impropriedades, do ponto de vista da norma culta, as incoerências apresentadas pelos alunos, por ocasião do processo de alfabetização, não eram vistas como indícios de um processo em curso de aquisição da representação escrita da linguagem, registrada e adquirida pelos alunos por observarem adultos e usuários da língua. Esses momentos revelam e tornam evidente a manipulação que a criança faz da própria linguagem: história da aquisição da escrita que a criança (re)constrói ao começar a ler e escrever.

Esse potencial cognitivo do "sujeito que aprende" foi proficientemente explorado por Ferreiro e Teberosky (1999) à luz da psicologia genética piagetiana.

Como educadores e formadores de professores para a Educação Infantil e Ensino Fundamental, propomos situações didáticas que permitam aos alunos avançarem a sua compreensão em relação à alfabetização apenas como domínio de código, processo este de fundamental importância no processo de aquisição da lectoescrita. Entretanto, tal processo complementase com o letramento, como processo de valorização e vivência do uso social de diferentes gêneros discursivos. Entendendo que esse acesso desencadeará o domínio da variedade lingüística que se quer que aprendam, construindo, assim, leitores proficientes. 
Alfabetizar e letrar, a partir da demanda que a sociedade necessita, é o grande desafio da educação do nosso século. Desafio para países como o Brasil, onde atravessamos o limiar do caos educacional com um grande contingente de analfabetos, incluindo-se, nesse contexto, crianças, jovens e adultos.

Muitos desses analfabetos são pessoas que, na época do seu período escolar inicial e regular, vivenciaram situações de exclusão social e econômica e/ou uma história de alfabetização marcada pela repetência, e sabemos que a sua aquisição da leitura e escrita pautou-se por um método mecanicista em que ensinar a ler e a escrever não ocorria como contexto de práticas sociais, uma vez que se valorizava mais o ensino da tecnologia da leitura e escrita, com textos descaracterizados e que só serviam para a instância escolar, para decodificações, memorizações e ensino de normas gramaticais, em detrimento da formação do aluno.

Acreditamos que, ao trabalharmos a aquisição da leitura e da escrita com o objetivo de alfabetizar letrando, a escrita cumpre a sua função social, em uma direção transformadora que aponta caminhos, que alerta, que não fica restrita à sala de aula, mas que esses conhecimentos e ensinamentos gerados se voltem para o mundo como possibilidade de interferência e transformação. E assim, de forma coletiva e crítica, todos o repensem este universo, vivendo o processo de uma cidadania, de fato, cidadã.

Assim sendo, os textos, no processo de ensino e aprendizagem relacionado à aquisição da escrita, requerem nova dimensão de produção e de abordagens, e, conseqüentemente, um novo professor/mediador, para a construção de uma nova sala de aula.

Kaufman e Rodriguez (1995), quando nos falam dos textos e das funções da linguagem, apontam para as diferentes intenções do emissor que essas unidades comunicativas contêm. Ou seja, os textos, às vezes, nos informam, em outras nos convencem, ou, ainda, querem nos seduzir. Para essas autoras: 
[...] o texto é o tapete: combina diferentes recursos da língua, combina diferentes classes de ações, seleciona palavras, privilegia determinadas relações sintáticas, etc. para transmitir diferentes intenções. Estes tecidos, estas tramas, são a narrativa, a argumentação, a descrição e a conversação (KAUFMAN e RODRIGUES, 1995, p. 16).

Pensarmos nessa dimensão de produção textual conduz-nos a um determinado modelo de educador. Perguntamos que modelo de professor/educador seduz o seu aluno por esse caminho, por essa trilha de encantamento com as letras?

Acreditamos que é aquele educador que teve a oportunidade e a predisposição para descobrir o prazer da leitura, de encontrar, na linguagem escrita, um meio de expressar "coisas do seu mundo", dos seus sentimentos, criando, assim, outros mundos, vivenciando a criação de textos que servem para a vida, para os diversos contextos sociais.

Acreditamos, também, que é aquele educador que vê e concebe os seus alunos com capacidades - como as suas -, de olhar, sensibilizar-se e de querer falar sobre o mundo que o cerca; é aquele que pesquisa, que busca alimentar-se, que consegue ver as reais necessidades e prazeres da leitura e da escrita. Ou seja, o educador que se apresenta para o seu aluno o conceber como modelo: de leitor, de escritor, de mediador, no seu processo de construção de conhecimentos.

Dessa forma, a sala de aula, para possibilitar a aprendizagem, não deve e nem pode resumir-se a um espaço físico nas dependências escolares, na qual se colocam carteiras "geralmente na mesma posição” e lousa: local em que os alunos entram, sentam-se, ouvem, repetem tarefas, copiam e saem.

Em contrapartida, a sala de aula deve ser concebida como um espaço onde se dá a inter-relação professor e alunos, alunos e alunos, acreditando que, de fato, nesse lugar, e a partir dele, acontece um diálogo dinâmico entre 
os envolvidos no processo de ensino e aprendizagem e todos saem modificados a cada encontro; onde o olhar de cada um consegue recortar e enxergar coisas (antes nunca vistas e nem experimentadas), uma vez que se trata de um micro e, concomitantemente, de um macro universo: a sala de aula.

Dessa forma, pode-se aceitar o "desafio que transcende amplamente a alfabetização em sentido estrito. O desafio que a escola enfrenta hoje é o de incorporar todos os alunos à cultura do escrito, é o de conseguir que todos seus ex-alunos cheguem a ser membros plenos da comunidade de leitores e escritores” (LERNER, 2002).

\section{CONSIDERAÇÕES FINAIS}

No processo de alfabetização, as práticas docentes- que adotam métodos voltados a ensinos descontextualizados e fragmentados cujas metas é decodificar e memorizar a equivalência entre as letras e os seus respectivos fonemas- colaboram com a perpetuação das diferenças entre as classes socialmente menos favorecidas e os segmentos sociais dominantes, e, conseqüentemente, com o sucesso escolar destes e o fracasso daquelas. Em contrapartida, em um processo de ensino e aprendizagem em que se consideram os conhecimentos prévios discentes como ponto de partida da aquisição de escrita, os textos são mapeados na rede das produções textuais que circulam socialmente no cotidiano do aluno, e as aprendizagens, construídas em interações mediadas pelos professores, são contextualizadas em espaços privilegiados à constituição de leitores críticos, autônomos: proficientes.

Os entraves que inviabilizaram, ao longo da história educacional brasileira, o acesso de crianças pertencentes às classes populares, às vagas disponíveis na rede pública de ensino foram muitos, no entanto, no contexto escolar, instalam-se possibilidades reais de consecução das metas previstas 
para o processo de ensino e aprendizagem; e - mais especificamente -, para a efetivação do ato de ler e escrever em um ambiente em que as salas de aulas podem se configurar, dependendo dos que nela atuam, em espaços para contatos com conhecimentos científicos significativos; e, assim sendo, a escola assume a sua importante função de instância sócio-cultural aberta a encontros qualitativos entre os discentes das diversas camadas sociais e o saber sócio-historicamente construído pela humanidade, para, dessa forma, colaborar com a construção de uma sociedade cidadã.

\section{Referências Bibliográficas}

BRANCO, Lisandre Castello (1997). O Trabalho Cotidiano do Professor na Escola - Novas Perspectivas. Revista do Congresso de Educação Continuada, Taubaté: UNITAU, dez.

BRASIL, (1988). Lei de Diretrizes e Bases da Educação Nacional, $\mathbf{n}^{\circ}$ 5692 de 11 de agosto de 1971. Brasília. São Paulo: Editora Moderna.

(2002). Lei de Diretrizes e Bases da Educação Nacional, no 9394 de 20 de dezembro de 1996. Brasília. São José dos Campos: Univap.

COLELLO, Silvia Mattos Gasparian (1995). Alfabetização em questão. Rio de Janeiro: Paz e Terra.

FERREIRO, Emilia \& Teberosky, Ana (1999). Psicogênese da Língua Escrita. Porto Alegre: Artes Médicas Sul.

FERREIRO, Emilia (1991). Reflexões sobre Alfabetização. São Paulo: Cortez.

FREIRE, Paulo (1985). Educação e mudança. Rio de Janeiro: Paz e Terra.

IANNI, Otávio (1971). Estado e Planejamento no Brasil (1930-1970). Rio de Janeiro: Civilização Brasileira. 
KAUFMAN, Ana Maria; RODRIGUES, Maria Helena (1995). Escola, leitura e produção de textos. Porto Alegre: Artmed.

KLEIMAN, Ângela (org.) (1995). Os significados do letramento: uma nova perspectiva da prática social da escrita. Campinas: Mercado das Letras.

LERNER, Delia (2002). Ler e escrever na escola: o real, o possível e o necessário. Porto Alegre: Artmed Editora.

PIAGET, Jean (1989). Seis Estudos de Psicologia. Rio de Janeiro: Forense Universitária.

RIBEIRO, Darcy (1995). A Alegria da Meninada e a Rua. Jornal Folha de São Paulo, 18 de setembro. Caderno Ilustrada, p. 1.

SÃO PAULO (Estado) (1987). Secretaria Municipal da Educação. Coordenadoria de Estudos e Normas Pedagógicas. Ciclo Básico. São Paulo: SE/CENP, 93p.

(1990). Secretaria Municipal da Educação. Coordenadoria de Estudos e Normas Pedagógicas. Ciclo Básico em Jornada Única: uma nova concepção de trabalho pedagógico. São Paulo: SE/CENP.

SILVA, Mariza Vieira da. História da Alfabetização no Brasil: a constituição de sentidos e do sujeito da escolarização. 1998. 202 f. Dissertação (Doutorado) - Universidade de Campinas, Campinas, 1998.

SOARES, Madga (1998). Letramento: um tema em três gêneros. Belo Horizonte: Autêntica. 


\title{
Autores:
}

\author{
Anézio Cláudio Bernardes \\ Professor no curso de Pedagogia do Instituto Superior de Educação - ISE, \\ da Universidade do Vale do Paraíba - UNIVAP. Pedagogo, Psicopedagogo \\ e Mestre em Lingüística Aplicada. \\ acb@univap.br
}

\section{Maria Angélica Gomes Maia}

Professora no curso de Pedagogia do Instituto Superior de Educação - ISE, da Universidade do Vale do Paraíba - UNIVAP. Pedagoga, Psicopedagoga, Arte-educadora e Mestre em Semiótica, Tecnologias de Informação e Educação.

mamaia@univap.br

\section{Vera Lúcia Catoto Dias}

Professora no curso de Pedagogia do Instituto Superior de Educação - ISE, da Universidade do Vale do Paraíba - UNIVAP. Pedagoga, Psicopedagoga e Mestre em Educação.

vcatoto@univap.br

\section{Ana Enedi Prince Silva}

Professora no curso de Pedagogia do Instituto Superior de Educação - ISE, da Universidade do Vale do Paraíba - UNIVAP.Historiadora e Doutora em História.

prince@univap.br

\section{Como citar este artigo:}

BERNARDES, Anézio Cláudio et al. Alfabetização e letramento: Construindo saberes essenciais. Revista ACOALFAplp: Acolhendo a Alfabetização nos Países de Língua portuguesa, São Paulo, ano 2, n. 4, 2008. Disponível em: <http://www.mocambras.org> e ou $<$ http://www.acoalfaplp.org>. Publicado em: março 2008. 